\title{
AC 2011-2776: DO STUDENTS GATHER INFORMATION TO INFORM DESIGN DECISIONS? ASSESSMENT WITH AN AUTHENTIC DESIGN TASK IN FIRST-YEAR ENGINEERING
}

\section{Ruth E. H. Wertz, Purdue University, West Lafayette}

Ruth E. H. Wertz is a graduate student in Engineering Education at Purdue University. She is a Professional Engineer in the State of Indiana, and holds BS and MS degrees in Civil Engineering from Trine University and Purdue University.

\section{Meagan C Ross, Purdue University, West Lafayette}

Meagan Ross is a Ph.D. student in the School of Engineering Education at Purdue University. She received a B.S. in Computer Science from Texas Woman's University, and a M.S. in Electrical Engineering from Texas Tech University. Prior to beginning her doctoral studies, she worked as a micro-optoelectromechanical systems engineer for Texas Instruments. Meagan began working for Institute for P-12 Engineering Research and Learning (INSPIRE) in the area of teacher professional development in 2009. Meagan is passionate about providing awareness of engineering to K-12 teachers \& counselors so that they can inform and advocate this important career to their students. Her research interests include gender equity in the K-12 Classroom, assessment of K-12 engineering education, curriculum development, and teacher professional development.

Mr. Michael Fosmire, Purdue University, West Lafayette

Dr. Monica E Cardella, Purdue University, West Lafayette

Monica E. Cardella is an Assistant Professor of Engineering Education and is the Co-Director of Assessment Research for the Institute for P-12 Engineering Research and Learning (INSPIRE) at Purdue University. Dr. Cardella earned a B.Sc. in Mathematics from the University of Puget Sound and an M.S. and Ph.D. in Industrial Engineering at the University of Washington. At the University of Washington she worked with the Center for Engineering Learning and Teaching (CELT) and the LIFE Center (Learning in Informal and Formal Environments). She was a CASEE Postdoctoral Engineering Education Researcher at the Center for Design Research at Stanford before beginning her appointment at Purdue. Her research interests include: learning in informal and out-of-school time settings, pre-college engineering education, design thinking, mathematical thinking, and assessment research.

\section{Senay Purzer, Purdue University, West Lafayette}

enay Purzer is an Assistant Professor in the School of Engineering Education and is the Co-Director of Assessment Research for the Institute for P-12 Engineering Research and Learning (INSPIRE) at Purdue University. Purzer has received her M.A. and Ph.D. degrees in Science Education at Arizona State University. She has a B.S. degree in Physics Education and a B.S.E. in Engineering. She has journal publications on instrument development, teacher professional development, and K-12 engineering education. Her creative research focuses on design problem-solving, collaborative learning, and assessment research. 


\title{
Do students gather information to inform design decisions? Assessment with an authentic design task in first-year engineering
}

\begin{abstract}
Information gathering is a very important aspect of the design process, one that is used continuously throughout the project to make informed design decisions. This study reports the development of an authentic instrument used to assess skills related to information gathering in first-year engineering students. Existing assessment tools, such as the scenario-based SelfKnowledge Inventory of Lifelong Learning (SKILLS), developed by Conti \& Fellenz, or the SelfDirected Learning Readiness Scale (SDLRS), developed by Guglielmino, were evaluated. While these have the advantage of being very easy to administer and analyze, one significant disadvantage is that they are self-reported and thus assess perceptions instead of demonstrated skills. For this study, we have developed a coding protocol to qualitatively evaluate written artifacts produced by first-year engineering students as part of their semester design project. The coding protocol identifies the classification, appropriateness, and documentation of individual sources used. The protocol also identifies overall strengths and weaknesses in regard to efficacy of information gathering, use of evidence to support arguments, and documentation of information sources across the artifact as a whole. In a sample of 25 randomly selected studentproduced memos from a pool of 263 , approximately $35 \%$ of the sources cited could not be classified due to poor documentation, $76 \%$ of the sources used were electronic sources, of which less than $20 \%$ were rated as high quality. These results suggest that students did not seek information from a variety of quality sources and that documentation was a significant weakness. Results from this study inform design instruction in future first-year engineering courses.
\end{abstract}

\section{Introduction}

Engineering in the twenty-first century is evolving and becoming more complex. The problems engineers encounter in the work force are ill-structured with constraints that extend beyond the reach of typical undergraduate engineering curricula, such as economic, social, political, environmental, and legal issues ${ }^{1}$. To compound this problem, global economic competition, growing environmental concerns, and rapid technological advancement place additional demands on engineers to be more innovative in the solutions they create. There have been several reports released in the last decade that call for engineers to become more skilled in communications, business, and economics, more creative and innovative, and more globally competent e.g. ${ }^{2,3-6}$. Engineers must develop superior information literacy competencies, such as the ability to critically and adeptly gather, evaluate, and synthesize information to be able to work within complex project constraints and ultimately meet the needs their organization, clients, and end users.

It is well established in the literature that information gathering is a critical step in the engineering design process. Moore, Atman, Bursic, Shuman, and Gottfried ${ }^{7}$ conducted a research study to evaluate how well first-year engineering (FYE) textbooks define the engineering design process. In this study, five of the seven textbooks analyzed discussed information gathering as a significant step in the overall design process. Further work by Atman and her colleagues evaluate and compare the design processes of first-year students, fourth-year 
students, and expert practitioners, and produce strong evidence of a relationship between information gathering skills and design quality ${ }^{8-11}$.

In addition to information gathering, it is also important for engineering students to develop competence in evaluating information for credibility and relevance. Where previous generations had to struggle with finding enough information relevant to a particular research problem, students in the Millennial Generation are inundated with information, only some of which is credible and relevant. This problem is compounded by the tendency of Millennials to equate technological literacy with information literacy, resulting in over confidence of their own ability to seek and evaluate information ${ }^{12}$. In a recent study comparing observations of information search behaviors of undergraduate students to Kuhlthau's ${ }^{13}$ Information Search Process (ISP) model, Holliday and $\mathrm{Li}^{14}$ suggest that students are skipping steps and ending the search process prematurely because they are satisfied with the volume of information they collected, despite a general lack of depth in coverage of the topic area they are researching. In general, undergraduate students use a very limited variety of information sources, and fail to critically evaluate the sources they do use ${ }^{15}$. Recent studies ${ }^{15-16}$ indicate that most students (71-94\%) are dependent on internet search engines (e.g. Google, Yahoo, Ask.com) as their primary search tool. In contrast, very few students (1-10\%) use academic search tools, such as databases and ejournals, to search for information. Brophy and Bawden ${ }^{17}$ report that for comprehensive coverage of a topic area, both internet search engines and database searches are needed, and as expected, the concentration of high quality sources in database searches is much higher (84\%) than information retrieved using Google (52\%).

Over the past decade, engineering educators and researchers are putting more emphasis on the importance of design, problem solving, lifelong learning, and by extension, information literacy in calls for engineering curriculum reform ${ }^{\text {e.g. } 18,19-21}$. The Accreditation Board for Engineering and Technology (ABET) has mirrored this emphasis in the Criterion 3 student outcomes, commonly referred to as the EC2000 a-k criteria. The following EC2000 criteria are relevant to information literacy and lifelong learning ${ }^{22}$ :

(a) an ability to apply knowledge of mathematics, science, and engineering

(e) an ability to identify, formulate, and solve engineering problems

(f) an understanding of professional and ethical responsibility

(g) an ability to communicate effectively

(h) the broad education necessary to understand the impact of engineering solutions in a global, economic, environmental, and societal context

(i) a recognition of the need for, and an ability to engage in life-long learning

(j) a knowledge of contemporary issues

Although the importance of lifelong learning has been codified in the ABET criterion 3.i, to date, there has been very little research reported on how to measure outcomes for that criterion ${ }^{23}$. The European Commission ${ }^{24}$ defines lifelong learning as "all learning activity undertaken throughout life, with the aim of improving knowledge, skills and competence, within a personal, civic, social, and/or employment-related perspective. Shuman, Besterfield-Sacre, and McGourty ${ }^{25}$ propose several attributes of lifelong learning, including the ability to "demonstrate reading, writing, listening, and speaking skills; demonstrate an awareness of what needs to be learned; 
follow a learning plan; identify, retrieve, and organize information; understand and remember new information; demonstrate critical thinking skills; and reflect on one's own understanding." Shuman, et al. argue that students' demonstration of these skills also demonstrate abilities of lifelong learning. Some of these skills could be classified as information literacy skills, particularly identifying, retrieving, and organizing information, which implies that information literacy is a component of lifelong learning. The purpose of this research is to investigate the baseline information literacy skills of FYE students by developing an assessment tool to evaluate written artifacts produced by students, either individually or in teams.

\section{Review of Lifelong Learning Assessment Tools}

Existing instruments designed for assessment of information literacy skills were considered for this research investigation. The Self-Directed Learning Readiness Survey (SDLRS) tool developed by Guglielmino ${ }^{26}$ was originally prepared as a predictive or diagnostic tool for students embarking in self-directed learning endeavors (e.g. distance learning, advanced degrees, professional certification, etc.). The instrument requires the user provide Likert-scale responses to 41 survey questions such as "I'm looking forward to learning as long as I'm living," "I love to learn," and "I know when I need to learn more about something ${ }^{26}$." The Self-Knowledge of Lifelong Learning Strategies (SKILLS) instrument developed by Conti and Fellenz ${ }^{27}$ is a scenario-based tool intended to measure responses to real-life adult learning situations, such as researching auto insurance, finding a job, arranging for health care for a relative, or fixing a bicycle. This instrument instructs the user to read the given scenario then organize a list of 18 scenario-specific strategies into three evenly distributed (i.e. 6 strategies in each) categories of "definitely use," "possibly use," and "not likely to use." The SKILLS assessment is scenariospecific which may help elicit more genuine responses than the general questions asked in the SDLRS assessment, however, both tools rely on self-reported information. As previously discussed, undergraduate students generally overestimate their information literacy competencies ${ }^{12}$, thus the investigators felt that self-reported data alone would not be an adequate measure of their actual skill-level. We concluded that an authentic assessment of demonstrated skills would better provide the information needed to ascertain the gaps in students' competence such that instructional interventions could be intelligently targeted to specific weaknesses.

\section{Research Questions}

The primary focus of this research study is to determine the gaps in information literacy competencies of first-year engineering (FYE) students; however, we hope that the results of this study will provide an example of evidence-based assessment of information literacy skills that could be replicated in other venues. The coding protocol used to evaluate students' written work was developed to address the following primary research questions: 1) What is the overall quantity and quality of the resources FYE students use, and 2) What are the overall strengths/weaknesses of FYE students' written work in regard to information gathering, building a strong argument, and documenting citations and in-text references?

In the development of the coding protocol, we expanded our two primary research questions into the following sub-questions: 


\section{Overall quality and quantity}

1. What kinds and how many resources do FYE students use in solving open-ended design problems?

2. What is the quality of the resources FYE students use?

\section{Strengths and Weaknesses}

3. Do FYE students consistently and accurately document sources of information?

4. Do FYE students use cited information appropriately to support design decisions?

5. What is the overall classification of FYE students' information gathering skill level?

6. What are the overall strengths/weaknesses of FYE students' written work in regard to information gathering, building a strong argument, and documenting citations and in-text references?

\section{Methodology}

\section{Research Setting}

The study was conducted in an introductory engineering course during the Fall semester. This introductory course provides the foundational experience for all engineers, and thus this is an excellent venue to introduce and assess baseline lifelong learning concepts. Three of the investigators for this research study have been actively involved in the development and teaching of this course.

The participants for this study consist of students enrolled in the FYE course in the Fall 2008 semester. The written artifacts produced by these students in fulfillment of regular course requirements were compiled and evaluated after the completion of the term. This research was carried out under IRB Approval 1008009557.

\section{Description of the Memo Assignment}

In the Fall 2008 semester of the introductory FYE course students were assigned a group project in which students teams were required to examine the buildings in which they lived and make recommendations on how to make the building more sustainable. Students were urged to consider a range of topics to make a case for where the biggest impact would be in making the building more sustainable. For example, considering the energy needs of heating and lighting, future energy costs, and environmental concerns of energy sources, were suggested in the project description as potential starting off points. There were several milestones for this project, including generating ideas, identifying and defining criteria and constraints, preparing the first draft of a memo communicating their recommendations, a peer review of the draft memo, and the final memo.

The project description was explicit in instructing students to justify their recommendations with data, evidence and rationale; however, there were no instructions given pertaining to the quantity or quality of sources, or citation style expected. The final memo was selected as the written artifact evaluated in this study. While the lack of information gathering and documentation instructions was not intended to benefit this study, it does provide a good baseline of what students produce without instructional interventions. 


\section{Sample Selection}

For this study 25 student memos were randomly selected from a pool of 263 and evaluated with a coding protocol developed by the investigators.

\section{Data Analysis Methods}

The instrument developed for this study consists of a six-part coding protocol (see Appendix), where each section of the protocol corresponds to a specific research question.

- Section 1 of the protocol was modeled after the citation categorization scheme used by Denick, Bhatt, and Layton ${ }^{28}$ in their citation analysis of engineering design reports. This section classifies the sources cited in the student memos by type of information resource. Note that sources with missing or incomplete citations, and/or missing or incomplete intext references were coded as "unknown" (UNKN). The code "general website" (GWEB) was given specifically to sources where the only element of the citation/reference given was a broken URL link. In this case it is known that the information source is a web resource, but the audience, purpose, and use of information cannot be evaluated.

- Section 2 assigns a general classification of audience and purpose to each source, which is used to assess its quality. For example, a source coded as scholarly $(\mathrm{SCH})$ and informative (INF) would be of high quality, and a source coded as popular (POP) and biased or for entertainment (BIAS/ENT) would be of low quality (see Figure 4).

- Section 3 assesses the students' documentation of each information source. This is divided into two categories, citation and in-text reference of the information resource. In cases where the citations were incomplete (CINC) or missing (CMIS), or the in-text references were incomplete (RINC) or missing (RMIS), the information source could not be coded beyond Section 1. If elements of the citation or in-text reference were missing, but the information source could still be identified, it was coded as improper (CIMP or RIMP).

- Section 4 evaluates how a particular thread of cited information was used in support of an argument. The first four sections of the coding protocol are applied to each information source, and thread of information generated from that source. In the cases where two or more independent threads of information originated from the same information source, treated as two different sources.

- Sections 5 and 6 of the protocol assess the overall quality of the memo as a whole.

Section 5 of the coding protocol assesses the level of information gathering demonstrated in the memo, and Section 6 identifies overall strengths and weaknesses in information gathering, constructing an argument, and documentation (citations and in-text references). 


\section{Inter-rater Reliability}

Inter-rater reliability for this protocol is was determined in several phases, starting with each investigator coding three memos to evaluate the quality and discuss weaknesses in the protocol. After several iterations, the final protocol was evaluated with two investigators coding two memos. The inter-rater reliability of the final protocol (94\%) was determined by dividing the actual number of agreements between the two investigators by the total possible number of agreements. The number of possible agreements are determined by the number of sources referenced in a given memo.

\section{Findings}

The results of the memos that were evaluated $(\mathrm{N}=25)$ are generally consistent with similar studies and citation analyses of undergraduate student information gathering and evaluation behaviors e.g. 12,16,17,28. The number of sources cited per memo ranged from 0 to 10 (mean $=3.3$, mode $=2$ ). The distribution of the quantity of citations per memo is shown in Figure 1. As expected, the web-based resources were the most frequent type of information cited (76\%), as shown in Figure 2. Within the web resources classification, commercial (24\%) and government (21\%) web pages were cited most frequently (see Figure 3 ).

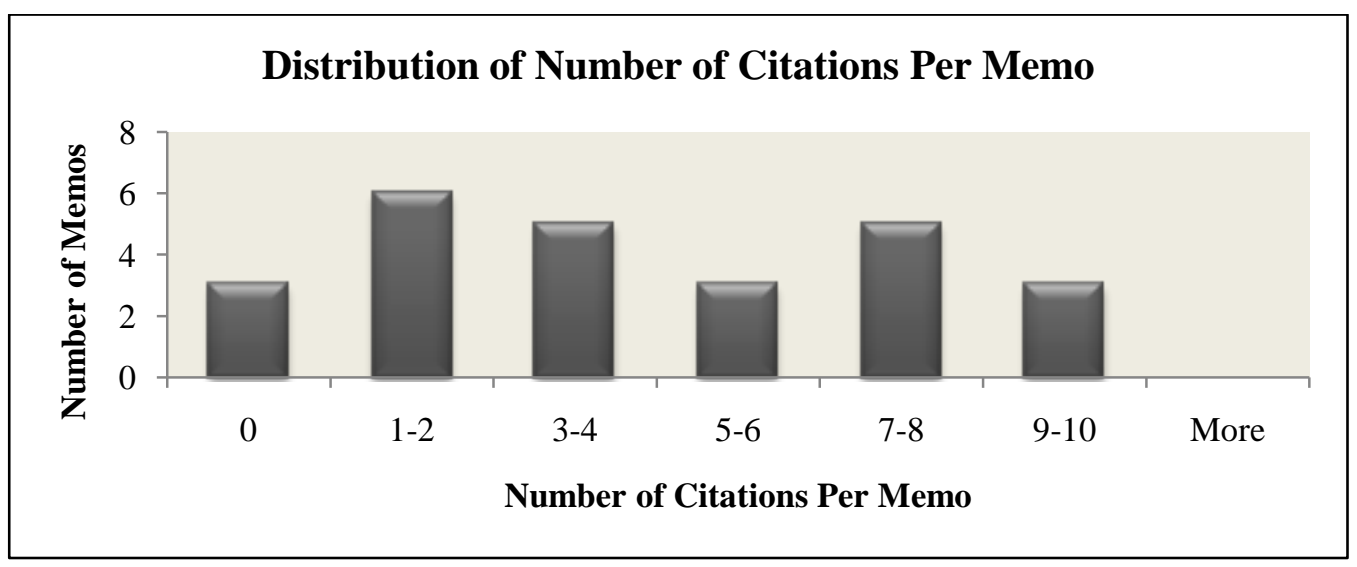

Figure 1: Number of information sources cited per memo within sample $(\mathrm{N}=25)$

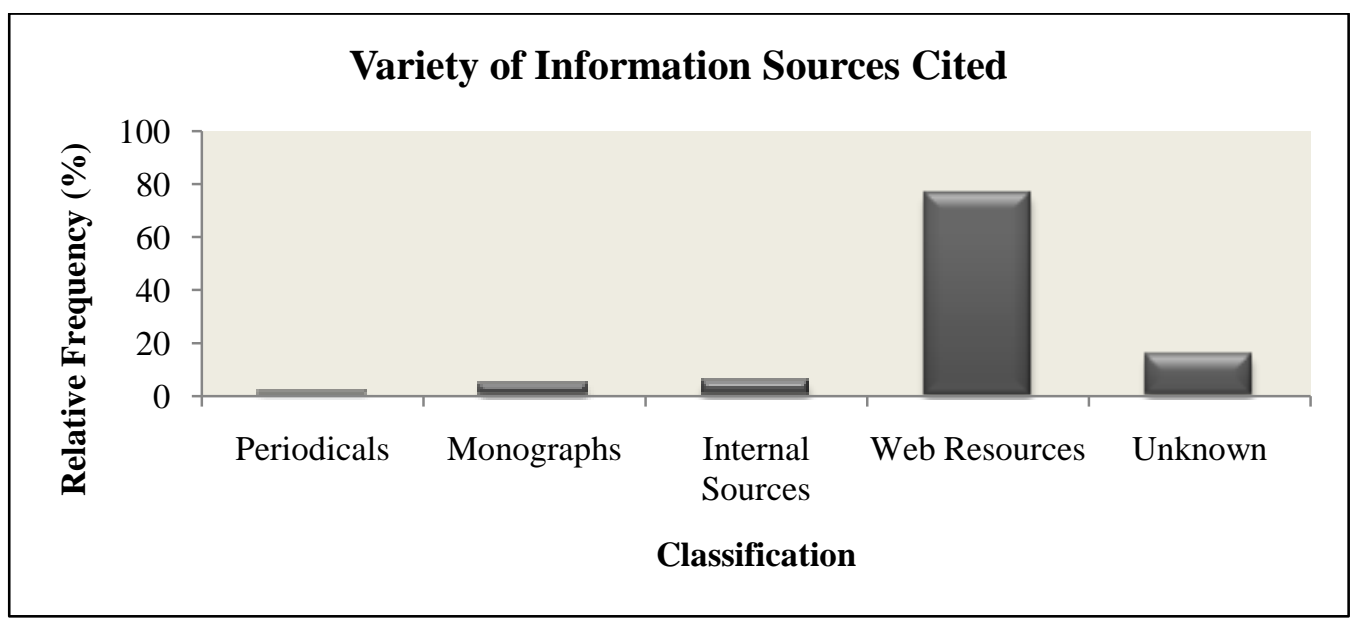

Figure 2: Variety of information sources cited within sample of memos $(\mathrm{N}=25)$ 
Within the sample of memos evaluated, there were references to 110 identifiable information sources, $40(35 \%)$ of these sources were coded as UNKN or GWEB due to incomplete information (Section 1 of coding protocol). The remaining 71 citations were assigned a quality rating of low, medium, or high based on the classification of audience and purpose (Section 2 of coding protocol). Overall, $18 \%$ of the cited sources were high quality, scholarly sources and the remaining $82 \%$ is split evenly between medium quality and low quality sources (see Figure 4). In a breakdown of the quality ratings per memo, only $15 \%$ of the memos evaluated in this study cited at least one high quality information source.

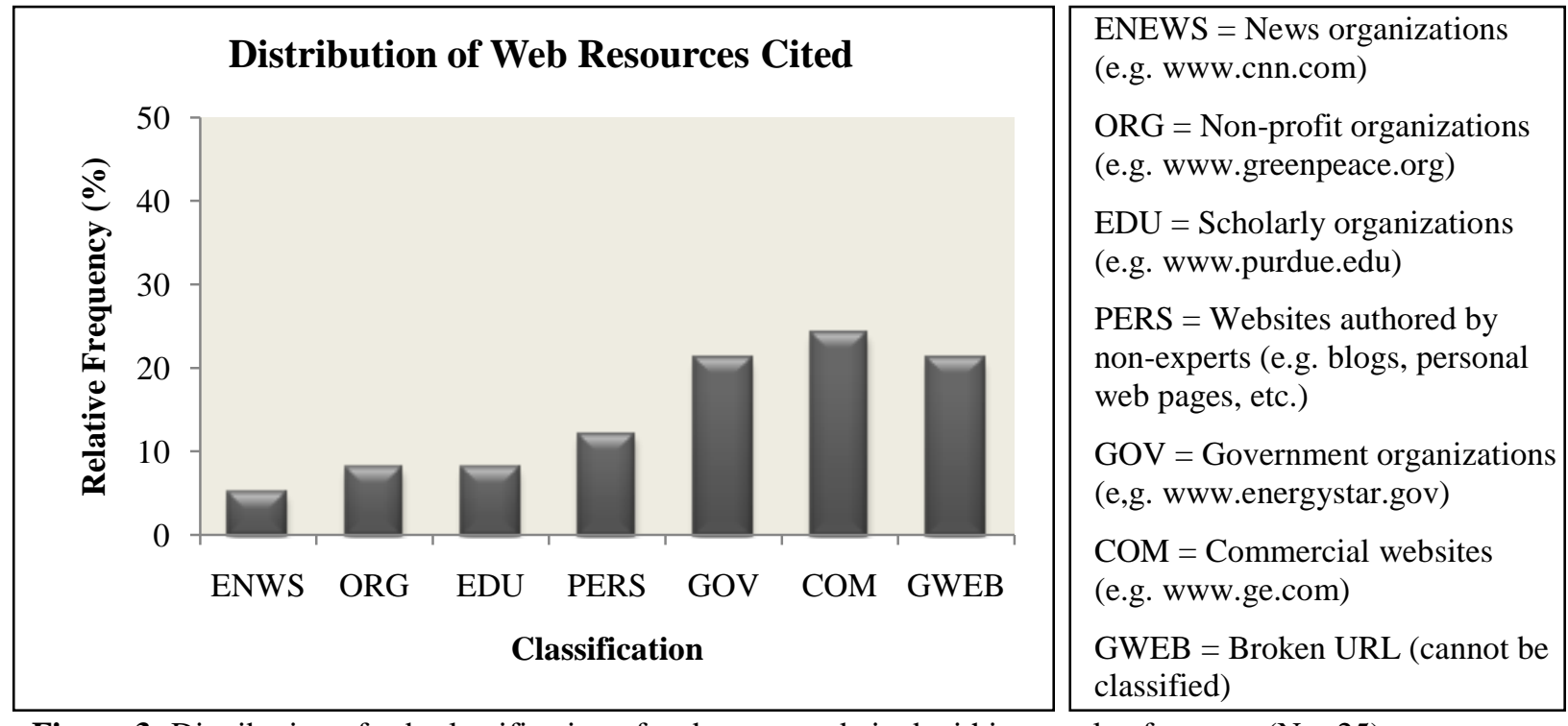

Figure 3: Distribution of sub-classification of web resourced cited within sample of memos $(\mathrm{N}=25)$

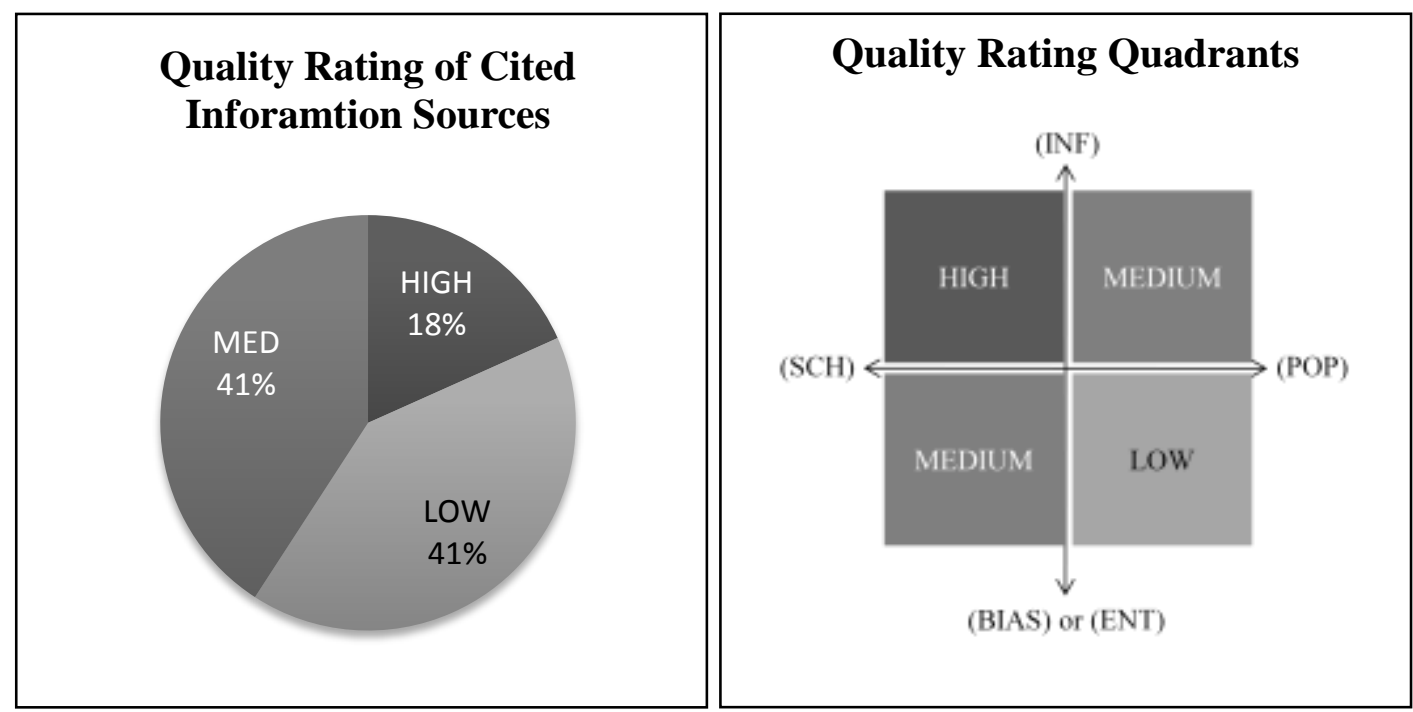

Figure 4: Quality rating of sources cited within sample of memos $(\mathrm{N}=25)$ (left) and Quality Rating Quadrants used to assign ratings (right) 
Of the original 110 identified information sources, $37 \%$ of these sources contained enough elements in the citation and in-text reference to evaluate the use of the information in support of the students' arguments. Furthermore, only 3\% of the identified sources had both complete citations and in-text references (CCOM and RCOM). Of the 41 threads of information that were evaluated, $71 \%$ was used appropriately, $22 \%$ was exaggerated (i.e. made generalizations from localized information, or made specific claims using general information, without making explicit assumptions of its applicability out of context), and 7\% was misrepresented (e.g. incorrect use of scientific data, used incorrect units, misused terminology, etc.).

As expected, the overall qualities of the memos reflected the quality of information gathered as well as the poor documentation skills demonstrated in the memos. For overall information gathering skill, $80 \%$ of the memos were classified as moderate to poor. Strong information gathering and argumentation were overall strengths demonstrated in $16 \%$ and $12 \%$ of the memo evaluated, respectively. The overall weaknesses observed were in documentation (84\% WCIT and/or WTXT) and information gathering (64\%)

\section{Discussion and Future Work}

The objective for this research was to better understand the baseline, demonstrated information literacy skills of first-year engineering students by using an authentic assessment tool to evaluate written artifacts produced by student teams. The results of this study are consistent with the

literature in that students exhibit weakness in both gathering and evaluating information ${ }^{12,17,28}$. A unique contribution of this study to the literature is the finding that students had very weak documentation skills. While no specific criteria regarding citation style (e.g. APA, MLA, etc.) was specified in the project description, providing citations for referenced material is a significant element of academic integrity and is discussed in detail in the syllabus, as well as in class at the beginning of most courses. Having such a small proportion (3\%) of citations and intext references be complete shows that students were not adequately prepared for this element of communication. It is possible that calling the final deliverable a "memo" instead of "report" caused students to think that providing citations was not necessary, however, this should have been addressed by the students between the first draft (milestone 3 ) and the final deliverable (milestone 5).

The results of this study suggests engineering faculty to engage in further collaborations with the Libraries to develop focused instructional interventions to help students improve their information gathering techniques, evaluation of information gathered from internet search engines, and documentation of works cited. In addition, this study provides an example for the development of authentic and evidence-based assessment of information literacy skills of a specialized group.

\section{Limitations}

Two types of information errors were frequently observed throughout the evaluation of the student memos. The first type of error observed was of students making assumptions instead of gathering the appropriate information. For example, one team made a general assumption of the local cost of electricity, instead of trying to find the information from the local power company. Another team made an assumption of how many kilowatt-hours (KWh) were used per month in a 
dorm building on campus, when this information is readily available on the University's website. The other type of error commonly observed was of information that appeared to be legitimately gathered, but was not cited or referenced. These observations were based on seeing similar threads of information cited in several other memos. In these cases it was not possible to conclusively determine if the information originated from similar sources seen in the other memos, or was assumed by the students. While the investigators suspect that a significant portion of "assumptions" made by students fall into the latter type of error we cannot divisively conclude this without further investigation. A possible avenue for future work would be to further investigate how much of the "weak information gathering" (WINF) and "weak argumentation" (WARG) was a result of poor information gathering versus poor documentation.

\section{Acknowledgements}

This work was supported by the Purdue University Engineer of 2020 Seed Grant "Developing Curious and Persistent Continuous Learners: Articulating and Assessing the Role of Information Skills in the First-Year Engineering Curriculum."

\section{References}

1. Jonassen, D., Strobel, J. \& Lee, C.B. Everyday Problem Solving in Engineering: Lessons for Engineering Educators. Journal of Engineering Education 95, 139-151 (2006).

2. National Intellegence Council. Global Trends 2025: A Transformed World, (U.S. Government Printing Office. www.dni.gov/nic/NIC 2025 project.html, Washington DC, 2008).

3. National Research Council. Rising aabove the Gathering Storm: Energizing and Employing America for a Brighter Future, (National Acemdies Press, Washington DC, 2007).

4. National Academy of Engineering. The Engineer of 2020: Visions of Engineering in the New Century, (National Academies Press, Washington, DC, 2004).

5. National Academy of Engineering. Grand Challenges for Engineering: Grand Challenges. (National Academy of Engineering, Washington, D.C., 2008).

6. National Academy of Engineering. Rebuilding a Real Economy: Unleashing Engineering Innovation, (National Academies Press, Washington DC, 2010).

7. Moore, P.L., Atman, C.J., Bursic, K.M., Shuman, L.J. \& Gottfried, B.S. Do Freshman Design Texts Adequately Define the Engineering Design Process? in Paper presented at the 2005 American Society for Engineering Eduaction Annual Conference \& Exposition (Portland, Oregon, 1995).

8. Atman, C.J., Chimka, J.R., Bursic, K.M. \& Nachtmann, H.L. A comparison of freshman and senior engineering design processes. Design Studies 20, 131-152 (1999).

9. Atman, C.J., Cardella, M.E., Turns, J. \& Adams, R. Comparing freshman and senior engineering design processes: an in-depth follow-up study. Design Studies 26, 325-357 (2005).

10. Atman, C.J., et al. Engineering Design Processes: A Comparison of Students and Expert Practitioners. 96, 359-379 (2007).

11. Bursic, K.M. \& Atman, C.J. Information Gathering: A Critical Step for Quality in the Design Process. Quality Management Journal 4, 60-75 (1997).

12. Brown, C., Murphy, T.J. \& Nanny, M. Turning Techno-Savvy into Info-Savvy: Authentically Integrating Information Literacy into the College Curriculum. Journal of Academic Librarianship 29, 386-398 (2003).

13. Kuhlthau, C.C. Seeking Meaning: A Process Approach to Library and Information Services, (Libraries Unlimited, Westport, CT, 2004).

14. Holliday, W. \& Li, Q. Understanding the Millenials: Updating Our Knowledge About Students. Reference Service Review 32, 356-366 (2004).

15. Shanahan, M.C. Transforming information search and evaluation practices of undergraduate students. International Journal of Medical Informatics 77, 518-526 (2008). 
16. Buhi, E.R., Daley, E.M., Fuhrmann, H.J. \& Smith, S.A. An Observational Study of How Young People Search for Online Sexual Health Information. Journal of American College Health 58, 101-111 (2009).

17. Brophy, J. \& Bawden, D. Is Google Enough? Comparison of an Internet Search Engine with Academic Resources. New Information Perspectives 57, 498-512 (2005).

18. Dym, C.L., Agogino, A.M., Eris, O., Frey, D.D. \& Leifer, L.J. Engineering Design Thinking, Teaching, and Learning. Journal of Engineering Education 94, 103-120 (2005).

19. Jamieson, L. \& Lohmann, J. Creating and Culture for Scholarly and Sytematic Innovation in Engineering Education. (American Society for Engineering Education, Washington, D.C., 2009).

20. Welker, A.L. \& Quintiliano, B. Information Literacy: Moving Beyond Wikipedia. in Geo-Congress 2008: Geosustainablilty and Geohazard Mitigation, Vol. 310 (eds. Krishna, R.R., Milind, V.K. \& Akram, N.A.) 97 (ASCE, New Orleans, LA, 2008).

21. Williams, B., Blowers, P. \& Goldberg, J. Integrating Information Literacy Skills into Engineering Courses to Produce Lifelong Learners. in 2004 American Society for Engineering Education Annual Conference \& Exposition (Salt Lake City, UT, 2004).

22. ABET. Criteria for Accrediting Engineering Programs: Effective for Evaluations During the 2011-2012 Accreditation Cycle. (ABET, Inc., 2010).

23. Shuman, L.J., Besterfield-Sacre, M. \& McGourty, J. The ABET 'Professional Skills'--Can they be taught? Can they be assessed? Journal of Engineering Education 94, 41-55 (2005).

24. European Commission. Lifelong Learning for Creativity and Innovation: A Background Report. (Slovenian EU Council Presidency, 2008).

25. Shulman, L. Signature pedagogies in the profession. Daedalus 134, 52-59 (2005).

26. Guglielmino, L.M. University of Georgia (1977).

27. Conti, G.J. \& Fellenz, R.A. Assessing Adult Learning Strategies, (ERIC ED339847, 1991).

28. Denick, D., Bhatt, J. \& Layton, B. Citation Analysis of Engineering Design Reports for Information Literacy Assessment. in 2010 American Society for Engineerin Education Annual Conference \& Exposition (Lousiville, KY, 2010). 


\section{Appendix - Coding protocol for FYE student memos (2010)}

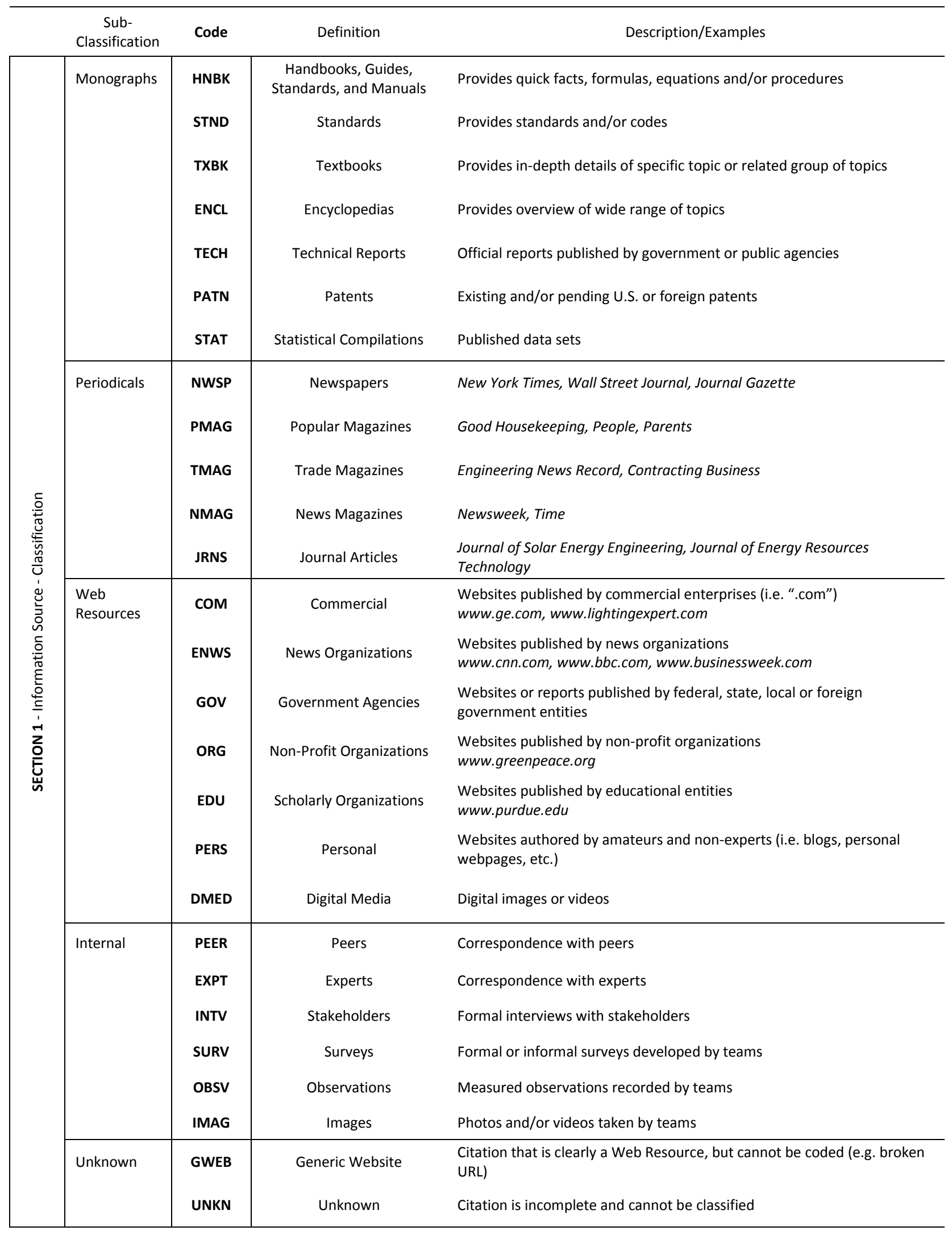




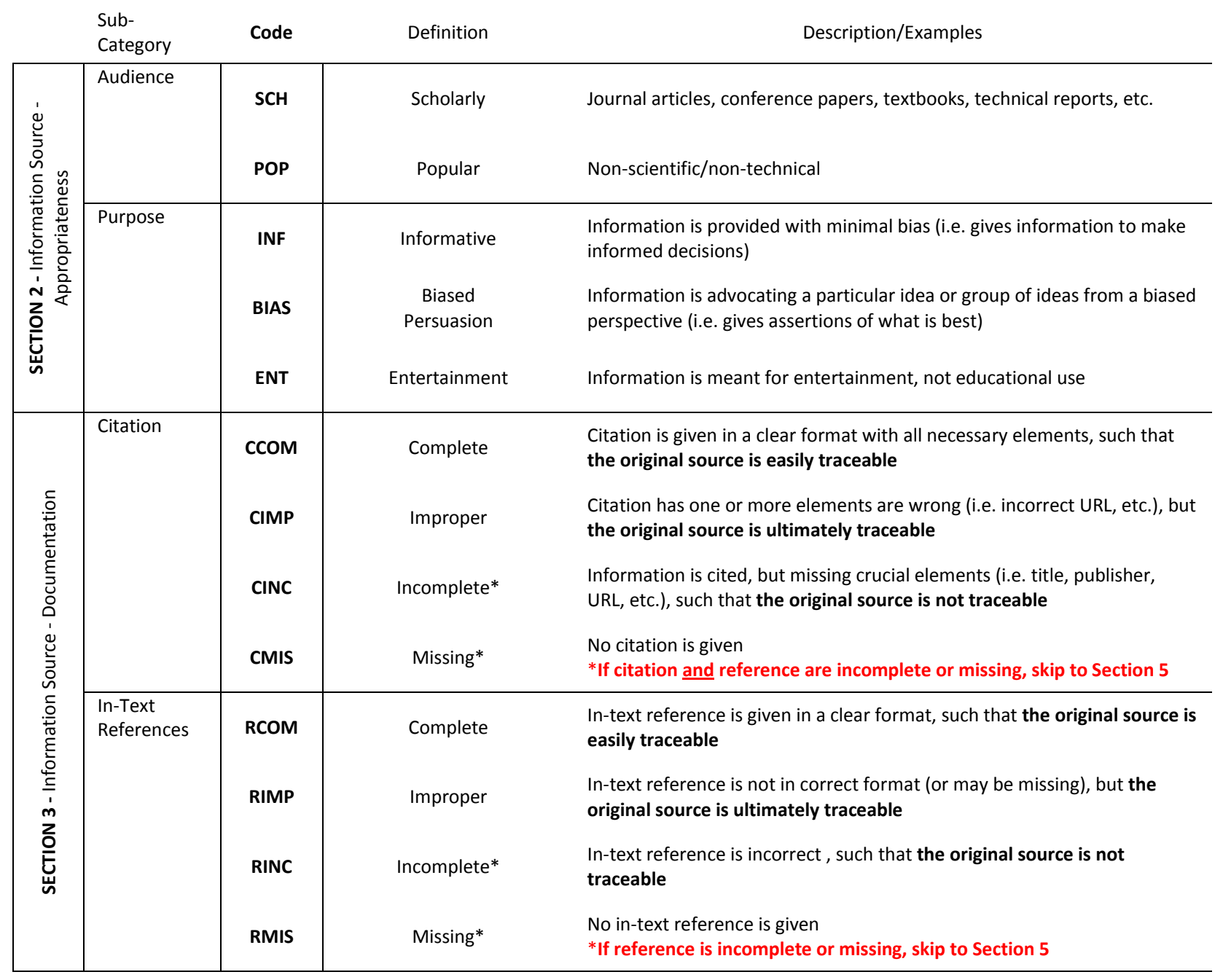

\begin{tabular}{|c|c|c|c|c|}
\hline & $\begin{array}{l}\text { Sub- } \\
\text { Category }\end{array}$ & Code & Definition & Description/Examples \\
\hline \multirow{6}{*}{ 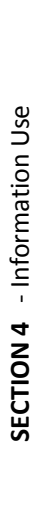 } & $\begin{array}{l}\text { General } \\
\text { Support }\end{array}$ & REL & Relevant & Information is relevant to the argument being made \\
\hline & & UNRL & Unrelated & Information is extraneous with no connection to the argument \\
\hline & Application & APPR & Appropriate & Information seems to be appropriately represented \\
\hline & & EXGG & Exaggerated & Information is either too general or too specific \\
\hline & & MISR & Misrepresented & $\begin{array}{l}\text { Information is misunderstood and/or taken out of context (i.e. incorrect } \\
\text { use of scientific calculation) }\end{array}$ \\
\hline & & INAP & Inappropriate & Information is taken from an unreliable or questionable source \\
\hline
\end{tabular}




\begin{tabular}{|c|c|c|c|c|}
\hline & & Code & Definition & Description/Examples \\
\hline 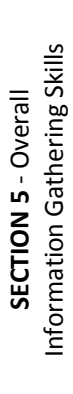 & 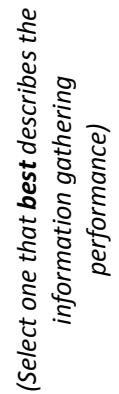 & $\begin{array}{l}\text { RICH } \\
\text { MODR } \\
\text { POOR }\end{array}$ & $\begin{array}{l}\text { Rich } \\
\text { Info Gathering } \\
\text { Moderate } \\
\text { Info Gathering } \\
\text { Poor } \\
\text { Info Gathering } \\
\text { No } \\
\text { Info Gathering }\end{array}$ & $\begin{array}{l}\text { Team uses information from four or more sources, at least three of } \\
\text { good quality, and some variety } \\
\text { Team uses information from one or sources, with one or two of good } \\
\text { quality } \\
\text { Team uses information from one or more sources, but all of poor } \\
\text { quality } \\
\text { Team fails to show any evidence of information gathering }\end{array}$ \\
\hline
\end{tabular}

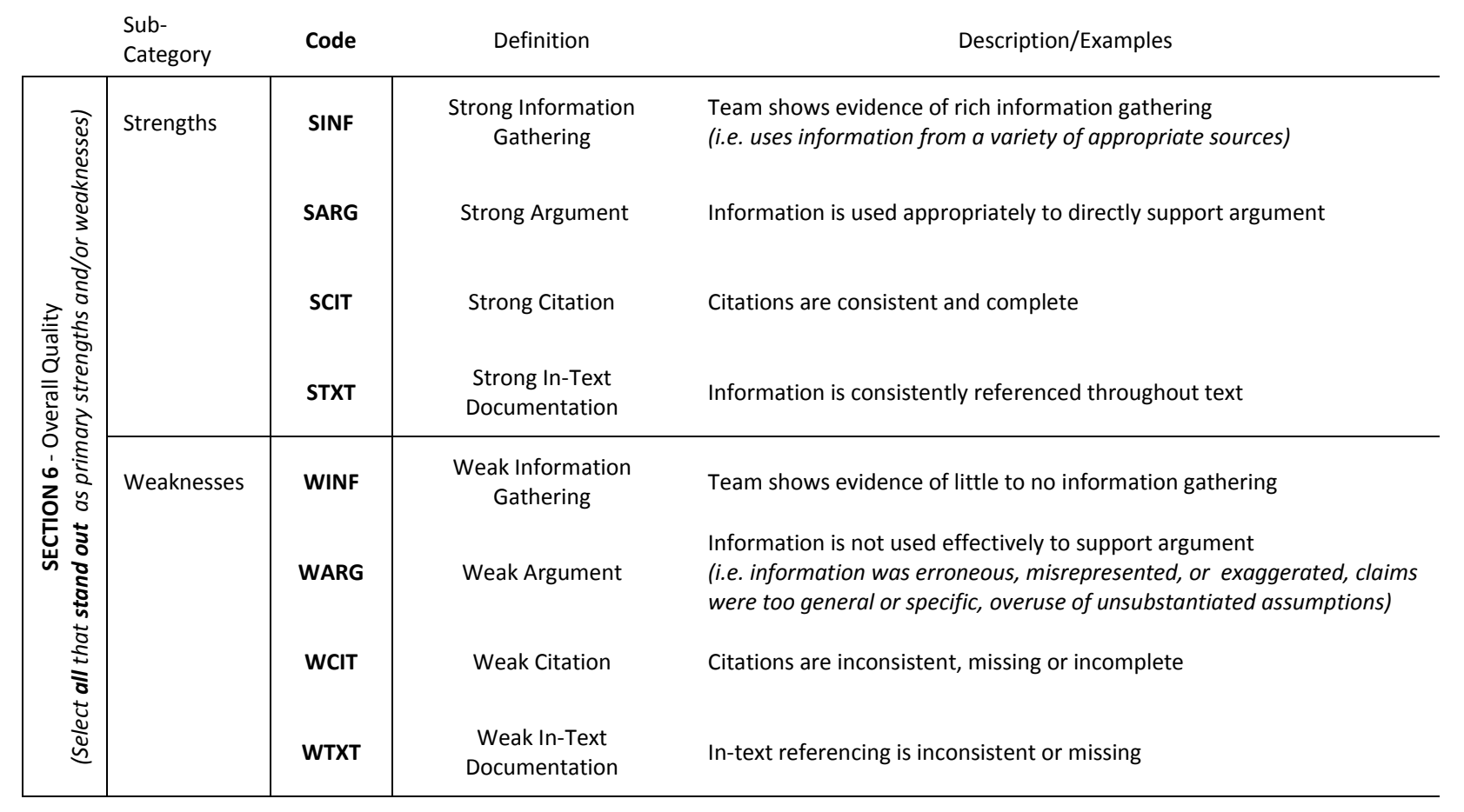

